\title{
ANALISIS BEBAN MENTAL KERJA DAN FISIK KARYAWAN PADA LANTAI PRODUKSI DENGAN METODE NASA-TLX DAN CARDIO VASCULAR LOAD (STUDI KASUS : PT. FAJAR UTAMA INTERMEDIA CABANG AMBON)
}

\author{
A. L. Kakerisa \\ Program Studi Teknik Industri, Fakultas Teknik Universitas Pattimura, Ambon \\ A. Soleman \\ Program Studi Teknik Industri, Fakultas Teknik Universitas Pattimura, Ambon \\ Bayu R. A. Prasetyo \\ Program Studi Teknik Industri, Fakultas Teknik Universitas Pattimura, Ambon
}

\begin{abstract}
ABSTRAK
PT.FUI Cabang Ambon merupakan perusahaan percetakan yang telah beroperasi di Ambon yang dimana awalnya hanya melayani salah satu media tertua dan terbesar di Maluku yaitu PT.Ambon Press, proses produksi dilakukan pada lantai produksi yang memiliki pekerjaan yang paling berat, karyawan bekerja di malam hari dan di tuntut untuk bekerja dalam keadaan berdiri serta terus menerus melakukan pergerakan tubuh dari waktu ke waktu untuk mengoperasikan mesin cetak dan merapikan hasil cetakan Koran, Dari segi ini juga sebagian karyawan yang berada di lantai produksi bukan hanya bekerja di malam hari saja, 3 orang karyawan memiliki pekerjaan lain setelah bekerja malam, dan 2 orang tidak ada pekerjaan lain setelah bekerja malam, hal ini menjadikan tekanan mental maupun fisik untuk 3 pekerja yang bekerja di waktu malam dan siang hari, hal tersebut akan menimbulkan masalah kesehatan dari pekerja karena tubuh dipaksa bekerja pada waktu malam dan siang. Penelitian ini bertujuan untuk mengidentifikasi tingkat beban kerja yang diterima pekerja baik secara mental dan fisik, keluhan yang dialami pekerja serta memberikan usulan waktu istirahat yang efektif,. Penelitian diawali dengan penyebaran kuisioner NASA-TLX kepada pekerja dibagian lantai produksi, selanjutnya metode CVL digunakan untuk mengetahui denyut nadi pekerja saat bekerja dan memberikan usulan waktu istirahat dengan menggunakan persamaan Murrel (Pullat, 1992). Berdasarkan hasil penelitian yang telah dilakukan kepada pekerja di bagian lantai produksi didapatkan nilai skor NASA-TLX sebesar 92,52 yang menunjukkan beban kerja yang diterima pekerja termasuk dalam ketegori beban kerja yang sangat tinggi. Berdasarkan hasil dari Pengukuran denyut nadi dengan metode CVL dengan hasil rata-rata untuk pekerja dibagian lantai produksi adalah sebesar 30,51\%, hasil tersebut menunjukkan pekerja harus melakukan perbaikan atas pekerjaannya. Hasil perhitungan dengan menggunakan persamaan Murrel (Pullat, 1992) diusulkan 21 jam waktu istirahat dan 3 jam untuk waktu kerja.
\end{abstract}

Kata Kunci: Cardiovascular Load, NASA-TLX, Persamaan Murrel (Pullat, 1992).

\begin{abstract}
PT. FUI Ambon branch is printing office that operates in Ambon and serves one of the oldest media PT. Ambon Press. Production process on the production floor has heavy work where as worker works on the standing position until night. The body movement of worker is to operate printing press and to arrange printed out of newspaper on the standing position continually. Beside, that duty, still three workers have another task and while two other without any other task. This situation causes both physical and physiological for three workers those are working at day and at night. Therefore, this study aims to identify level of workload of workers both physically and mentally and to suggest the effective rest time. The NASA$T L X$ questionnaire has sent to the workers on the production floor, then by applying CVL method, the pulse of workers is measured while working, and suggestion of rest time is formulated using Murell formula. The result of the research shows that NASA-TLX score is 92.52 that mean the workload of workers is categorized very high. While the average of pulse of workers is $30.51 \%$ which indicates the worker has to improve their work. The result of Murell formula shows that the workers have to have 21 hours rest time and 3 hours working time.
\end{abstract}

Keywords: Cardiovascular Load, NASA-TLX, Murrel Formula . 


\section{PENDAHULUAN}

Setiap pekerja mempunyai beban kerja yang berbeda sesuai dengan jenis pekerjaanya. Beban kerja tersebut berpengaruh pada kondisi fisik maupun psikis yang dapat menimbulkan dampak kelelahan bagi pekerja. Menurut Kementrian Kesehatan RI (2014) kelelahan kerja akan menyebabkan terjadinya penurunan produktivitas kerja yang dapat meningkatkan jumlah terjadinya perubahan pada perilaku kerja, kesalahan kerja, ketidakhadiran kerja, berhenti bekerja, dan kecelakaan kerja.

Beberapa penelitian yang telah dilakukan, kelelahan kerja memberi kontribusi $50 \%$ terhadap terjadinya kecelakaan kerja (setyawati, 2007). Kelelahan bisa terjadi oleh sebab fisik ataupun tekanan mental. Salah satu penyebab fatique adalah gangguan tidur (sleep distruption) yang antara lain dapat dipengaruhi oleh kekurangan waktu tidur dan gangguan pada circadian rhythms akibat pemberlakuan shift kerja (Wicken, et al, 2004). Sudah dipercaya bahwa sebagian besar dari pekerja yang bekerja pada shift malam memiliki risiko yang lebih tinggi mengalami kecelakaan dibandingkan mereka yang bekerja dalam keadaan normal (shift pagi) (Jostling,1998). Dalam artikelnya yang berjudul Shift Work and III- Health mempertegas anggapan tersebut dengan menyebutkan hasil penelitian yang dilakukan oleh The Circardian Learning Center di Amerika yang menyatakan bahwa para pekerja shift, terutama yang bekerja di malam hari, dapat terkena beberapa permasalahan kesehatan. Permasalahan kesehatan ini antara lain; gangguan tidur, kelelahan, dll. Segala gangguan kesehatan tersebut ditambah dengan tekanan stress yang besar dapat otomatis meningkatkan risiko terjadinya kecelakaan pada pekerja shift malam.

PT Fajar Utama Intermedia Cabang Ambon (FUI) merupakan salah satu perusahaan anak dari Harian Fajar Group. Devisi percetakan ini awalnya, lahir dari sebuah percetakan umum tahun 1980 an dengan nama CV Centra Bakti Baru. Percetakan ini kemudian mencetak Koran harian Fajar dan groupnya disamping cetakan-cetakan umum lainnya. Dalam hal pekerjaan pemerintah, PT FUI telah mencetak beberapa buah buku autobiografi, majalah, Koran harian Ambon Express, tabloid, stiker, brosur dll. Soalsoal ujian SD, SMP - SLTP, SMA SLTA juga telah lama dikerjakan perusahaan ini. Karyawan memproduksi Koran dan lainnya pada pukul 01:00-04:00 WIT. Artinya waktu tersebut diluar dari jam kerja normal (pagi) adalah waktu lembur. (Grandjean, 1991). Sistem kerja dipandang sebagai tuntutan yang menekan individu. Rentang Umur karyawan PT. FUI berkisar 40-50, hal ini menunjukan umur karyawan PT. FUI jauh dari usia produktif, sehingga sangat mempengaruhi kondisi kerja baik secara fisik maupun mental. Pekerjaan yang dilakukan pada lantai produksi PT. Fajar Utama Intermedia (FUI) cabang Ambon tergolong pada jenis pekerjaan yang memiliki intensitas kerja yang sangat tinggi karena adanya tekanan dan tegangan dalam menyelesaikan pekerjaan. Hal ini dapat dilihat berdasarkan cara kerja karyawan dituntut bekerja di malam hari dalam posisi berdiri dan harus berkonsentrasi dengan durasi waktu yang lama. Karyawan juga melakukan pergerakan tubuh secara terus menerus untuk mengoperasikan mesin cetak dan merapikan hasil cetakan koran.

Tekanan fisik maupun mental yang dialami karyawan PT. FUI, adalah dengan adanya aktivitas karyawan pada lantai produksi yang harus bekerja pada kondisi lingkungan yang tidak sesuai. Dari segi ini juga sebagian karyawan yang berada di lantai produksi bukan hanya bekerja di malam hari saja, 3 orang karyawan memiliki pekerjaan lain setelah bekerja malam, dan 2 orang tidak ada pekerjaan lain setelah bekerja malam, hal ini menjadikan tekanan mental maupun fisik untuk 3 pekerja yang bekerja di waktu malam dan siang hari, hal tersebut akan menimbulkan masalah kesehatan dari pekerja karena tubuh dipaksa bekerja pada waktu malam dan siang, jadi mereka tidak dapat istirahat dengan baik. Belum lagi jika pemadaman listrik oleh PLN dan seringnya terjadi keterlambatan penyediaan bahan baku, kegiatan produksi akan terhambat karena mesin butuh energy listrik dan bahan baku yang kurang. Hal ini sangat mempengaruhi beban kerja mental yang sangat tinggi mengakibatkan frustasi karena di tuntut kerja cepat setelah terhambat oleh pemadaman listrik dan bahan baku yang kurang tersebut. Jika sistem kerja dan fasilitas tidak dikelolah dengan baik oleh perusahaan ataupun instansi akan berdampak gangguan fisiologis dan psikologis, dan pada akhirnya akan mengurangi produktivitas pekerja.

Oleh karena itu, perlu untuk mengidentifikasi tingkat beban kerja yang diterima pekerja baik secara mental dan fisik, keluhan yang dialami pekerja serta dapat memberikan usulan waktu istirahat yang efektif sehingga akan meningkatkan produktivitas kerja karyawan PT. FUI cabang Ambon.

\section{LANDASAN TEORI Ergonomi}

Berdasarkan pengertian ergonomi menurut pusat kesehatan kerja departemen kesehatan kerja RI, ergonomi yaitu ilmu yang mempelajari perilaku manusia dalam kaitannya dengan pekerjaan mereka. Sasaran penelitian ergonomi ialah manusia pada saat bekerja dalam lingkungan. Secara singkat dapat dikatakan bahwa ergonomi ialah penyesuaian tugas pekerjaan dengan kondisi tubuh manusia ialah untuk menurunkan stress yang akan dihadapi.

Menurut pusat kesehatan kerja departemen kesehatan RI, upaya ergonomi antara lain berupa menyesuaikan ukuran tempat kerja dengan dimensi tubuh agar tidak melelahkan, pengaturan suhu, cahaya 
dan kelembaban bertujuan agar sesuai dengan kebutuhan tubuh manusia. Definisi lain menyebutkan bahwa ergonomi adalah sebuah ilmu untuk "fitting the job to the worker", sementara itu ILO antara lain menyatakan, sebagai ilmu terapan biologi manusia dan hubungannya dengan ilmu teknik bagi pekerja dan lingkungan kerjanya, agar mendapatkan kepuasan kerja yang maksimal selain meningkatkan produktivitasnya.

Tujuan dari penerapan ergonomi adalah:

1. Angka cedera dan kesakitan dalam melakukan pekerjaan tidak ada terkurangi

2. Biaya terhadap penanganan kecelakaan atau kesakitan menjadi berkurang

3. Kunjungan untuk berobat bisa berkurang

4. Tingkat absentisme/ ketidak hadiran bisa berkurang

5. Produktivitas/ kualitas dan keselamatan kerja meningkat

6. Pekerja merasa nyaman dalam bekerja

Beberapa metode dalam artikel ergonomi dari departemen kesehatan Republik Indonesia, dalam menilai ergonomis atau tidaknya suatu lingkungan kerja, yaitu:

1. Diagnosis, dapat dilakukan melalui wawancara dengan pekerja, inspeksi tempat kerja penilaian fisik pekerja, uji pencahayaan, ergonomik checklist dan pengukuran lingkungan kerja lainnya. Variasinya akan sangat luas mulai dari yang sederhana sampai kompleks.

2. Treatment, pemecahan masalah ergonomi akan tergantung data dasar pada saat diagnosis. Kadang sangat sederhana seperti merubah posisi meubel, letak pencahayaan atau jendela yang sesuai. Membeli furniture sesuai dengan demensi fisik pekerja.

3. Follow-up, dengan evaluasi yang subyektif atau obyektif, subyektifmisalnya dengan menanyakan kenyamanan, bagian badan yang sakit, nyeribahu dan siku, keletihan, sakit kepala dan lain-lain. Secara obyektifmisalnya dengan parameter produk yang ditolak, absensi sakit, angka kecelakaan dan lain-lain.

\section{Circadian Ritme (Irama Diurnal)}

Bermacam-macam fungsi tubuh manusia dan hewan brfluktuasi dalam siklus 24 jam,dinamakan circadian rhythm (atau irama diurnal).Meskipun jika pengaruh normal dari siang dan malam diabaikan, contohnya di Artic, atau dalam sebuah ruangan tertutup dengan pencahayaan buatan, sejenis jam internal dimainkan, atau biasa juga disebut endogenous rhythm. Ritme ini bervariasi tiap individual, tetapi beroperasi dalam siklus antara 22 dan 25 jam (Nurmianto,2004).

Dalam keadaan normal endogenous rhythm disamakan menjadi siklus24 jam dengan bermacammacam "pemeliharaan waktu"(Nurmianto, 2004): (a) Perubahan dari siang ke malam dan semacamnya; (b) Kontak sosial; (c) Pekerjaan; dan (d) Pengetahuan waktu jam Circadian rhythm yang sudah sangat dikenal adalah ritme temperatur tubuh,yang menunjukan fluktuasi harian yang berkisar $0,5^{\circ} \mathrm{C}$ yang merupakan sisi lain nilai pokok dari $37^{\circ} \mathrm{C}$. Siklus mencapai titik terendah sekitar pukul 04.00,dan mulai meningkat lagi sekitar pukul 06.00 (umumnya sebelum seseorang bangun) dan meningkat tajam sampai tengah hari dan lebih lambat sesudahnya. Temperatur puncak dicapai di titik manapun antara tengah hari dan malam hari, tetapi paling banyak pada pukul 18.00 dan 21.00. Mulai pukul 20.00 dan seterusnya, temperatur mulai menurun secara tajam. Menurut Minors dan Waterhouse(1985), terdapat perubahan siklus yang hampir sama dalam jantung, pernapasan dan fungsi kelenjar ginjal, tekanan darah, sekresi endokin yang bemacam-macam, dan sebagainya meskipun mencapai puncak dan lembah pada waktu yang berbeda.

Selama malam, fungsi fisiologi benilai rendah, sebagai contoh suhu inti dan detak jantung mengawali irama diurnal tubuh. Yang didukung oleh ketidak aktifan pada malam hari dan puasa. Selama siang aktivitas puncak biasanya bertepatan dengan nilai tinggi dari fungsi internal. Biasanya pengamatan irama diurnal diperoleh berdasarkan hasil internal (endogenous) dan eksternal (exogenous) yang terjadi. Jika terjadi ketidak seimbangan antara keduanya tersebut dapat muncul permasalahan kesehatan.

\section{Definisi Stress}

Stress bukanlah hanya hal-hal yang membuat cemas melainkan meliputi semua keadaan,baik sedih maupun bahagia, alergi, sakit fisik, keadaan yang tidak diharapkan, dan sebagainya. Tubuh mempunyai definisi stress lebih luas. Bagi tubuh, stress identik dengan perubahan. Apa pun yang membuat perubahan dalam kehidupan bisa menyebabkan stress baik itu perubahan baik ataupun buruk. Adapun jika perubahan itu tidaknyata (masihada dalam pikiran) disebut kecemasan (Nurmianto, 2004). Terdapat beberapa macam stress antara lain (Nurmianto, 2004):

1. Stress Emosional

Bila pertengkaran, pertentangan pendapat, dan konflik menyebabkan perubahan dalam kehidupan yang dijalani, itulah stress. 
2. Stress Fisik

Sekedar Flu, atau patah tulang, infeksi kulit,nyeri punggung, semuanya adalah perubahan pada tubuh yang menyebabkan stress. Penyebab utama stress fisik adalah terlalu memaksakan diri dalam segala hal. Jika tubuh dipaksa bekerja (atau berpesta) 16 jam sehari, maka dapat mengurangi waktu istirahat. Cepat atau lambat, persediaan energi akan habis, tidak sesuai dengan energi yang didapat.Hal ini mengakibatkan tidak adanya waktu yang cukup bagi tubuh untuk memperbaiki sel-sel yang rusak, menggantikan neurotransmiter otak yang sudah digunakan. Dengan demikian, akan terjadi perubahan pada organ-organ tubuh, termasuk jantung dan pembuluh darah.Jika hal ini terus menerus berlangsung maka kerja jantung akan terganggu.

3. Stress Lingkungan

Lingkungan yang terlalu panas (AC mati ) atau dingin (AC terlalu dingin) juga dapat menyebabkan stress. Ketinggian (termasuk naik pesawat) juga membuat stress. Demikian juga racun dari lingkungan. Semuanya menyebabkan perubahan yang mengakibatkan stress.

4. Stress Asap Rokok

Asap rokok adalah racun yang sangat kuat.Asapnya menghancurkan sel-sel yang bertugas membersihkan kerongkongan, saluran napas, sampai paru- paru serta dapat menyebabkan emfisema dan bronkhitis kronis. Selain itu juga dapat menyebabkan kerusakan pembuluh darah sehingga pasokan darah ke otak, jantung dan organ vital lainnya berkurang. Penggunaan tembakau dengan cara lain, termasuk mengunyah sirih, juga sama bahayanya.

5. Perubahan Stress Hormonal

Perubahan hormonal seperti masa pubertas dan sindroma premenstrual juga menyebabkan stress. Hal lainnya seperti kondisi setelah melahirkan dan menopause.

7. Sress Tanggung Jawab

Bila seseorang harus bertanggung jawab atas pekerjaan orang lain,perubahan dalam hidup menyebabkan ia tidak mempunyai kontrol.Misalnya, temankerja tidakmasuk, ia harus menggantikan tugasnya.

\section{Kelelahan}

Kelelahan adalah aneka keadaan yang disertai penurunan efisiensi dan

Ketahanan dalam bekerja,yang dapat disebabkan oleh:

1. Kelelahan yang sumber utamanya adalah mata (kelelahan visual)

2. Kelelahan fisik umum

3. Kelelahan syaraf

4. Kelelahan oleh lingkungan yang monoton

5. Kelelahan oleh lingkungan kronis terus-menerus sebagai factor secara menetap (Suma'mur,1999).

Menurut Nurmianto (2004), kelelahan kerja akan menurunkan kinerja dan menambah tingkat kesalahan kerja. Meningkatnya kesalahan kerja akan memberikan peluang terjadinya kecelakaan kerja dalam industri.Pembebanan otot secara statis pun (staticmuscular loading) jika dipertahankan dalam waktu yang cukup lama akan mengakibatkan RSI (Repetition Strain Injuries), yaitu nyeri otot, tulang, tendon, dan lain-lain yang diakibatkan oleh jenis pekerjaan yang bersifat berulang (repetitive).

\section{Denyut Nadi}

Denyut nadi adalah frekuensi irama denyut/detak jantung yang dapat dipalpasi (diraba) dipermukaan kulit pada tempat-tempat tertentu (Depdikbud,1996). Siklus jantung terdiri dari periode relaksasi yang dinamakan diastole dan diikuti oleh periode kontraksi yang dinamakan systole. Kekuatan darah masuk kedalam aorta selama sistolik tidakhanya menggerakkan darah dalam pembuluh ke depan tetapi juga menyusun suatu gelombang tekanan sepanjang arteri. Gelombang tekanan mendorong dinding arteri seperti berjalan dan pendorongnya teraba sebagai nadi. Pada jantung manusia normal, tiap-tiap denyut berasal dari noddus SA (iramasinus normal, NSR = Normal Sinus Rhythim) waktu istirahat jantung berdenyut kirakira 70 kali kecepatannya berkurang waktu tidur dan bertambah karena emosi, kerja, demam, dan banyak rangsangan yang lainnya (Guyton,1997).

Denyut nadi seseorang akan terus meningkat bila suhu tubuh meningkat kecuali bila pekerja yang bersangkutan telah beraklimatisasi terhadap suhu udara yang tinggi. Denyut nadi maksimum untuk orang dewasa adalah 180-200 denyut permenit dan keadaan ini biasanya hanya dapat berlangsung dalam waktu beberapa menit saja (Siswanto,1978). 


\section{Beban Kerja Mental}

Untuk mengukur beban kerja mental, salah satu metode yang dapat digunakan adalah National Aeronautics and Space Administration Task Load Index (NASA-TLX). Metode ini di kembangkan berdasarkan munculnyan kebutuhan pengukuran subjektif yang terdiri dari skala Sembilan factor (Kesulitan tugas, tekanan waktu, jenis aktivitas, usaha fisik, usaha mental, performansi, frustasi, stress dan kelelahan). Dari Sembilan faktor ini disederhanakan lagi menjadi 6 yaitu: Kebutuhan Mental demand (MD), Physical demand (PD), Temporal demand (TD), Performance (P), Frustation level (FR). (Hidayat dkk, 2013).

Pengukuran beban kerja mental ini dapat dilakukan secara umum dengan tiga cara, yaitu sebagai berikut(Mariawati, 2013):

1. Pengukuran beban kerja secara obyektif,

2. Pengukuran beban kerja secara pemilihan tugas,

3. Pengukuran beban kerja secara subyektif.

\section{Beban Kerja}

Beban kerja meliputi beban kerja fisik dan mental. Akibat beban kerja yang terlalu berat atau kemampuan fisik yang terlalu lemah dapat mengakibatkan seorang pekerja menderita gangguan atau penyakit akibat kerja. Kondisi lingkungan kerja (panas, bising, debu, zat-zat kimia)dapat merupakan beban tambahan terhadap pekerja. Beban-beban tambahan tersebut secara sendiri atau bersama dapat menimbulkan gangguan atau penyakit akibat kerja.Gangguan kesehatan pada pekerja dapat disebabkan oleh factor yang berhubungan maupun yang tidak berhubungan dengan pekerjaan. Dengan demikian status kesehatan pekerja dipengaruhi tidak hanya oleh bahaya kesehatan di lingkungan kerja tetapi juga oleh factor pelayanan kesehatan kerja, perilaku kerja serta faktor lainnya.

Menurut Rodahl (1989), dan Manuaba (2000) hubungan antara beban kerja dan kapasitas kerja dipengaruhi oleh factor internal dan eksternal.

1. Beban Kerja Karena Faktor Eksternal

Beban kerja eksternal adalah tugas itu sendiri, organisasi dan lingkungan kerja.

2. Beban Kerja Karena Faktor Internal

Faktor internal beban kerja adalah factor sebagai akibat adanya reaksi beban kerja eksternal, yang mana reaksi tubuh tersebut disebut strain.Berat ringan strain dapat dinilai :

1) Secara objektif melalui perubahanreaksi psikologis dan perilaku,

2) Secara subjektif melalui harapan,keinginan, dan kepuasan kerja. Secara ringkas faktor internal meliputi :

a. Faktorsomatis (jenis kelamin, umur, ukuran tubuh,kondisi kesehatan, gizi).

b. Faktor psikis (motivasi, persepsi, kepercayaan, keinginan, kepuasan).

\section{Pengaruh Waktu Kerja dan Waktu Istirahat}

Pengaturan waktu istirahat harus disesuaikan dengan sifat, jenis pekerjaan dan faktor lingkungan yang mempengaruhinya seperti lingkungan kerja panas, dingin, bising dan berdebu. Namun demikian secara umum, diIndonesia telah ditentukan lamanya waktu kerja sehari maksimum adalah 8 jam kerja dan selebihnya adalah waktu istirahat. Memperpanjang waktu kerja lebih dari itu hanya akan menurunkan efisiensi kerja, meningkatkan kelelahan, kecelakaan dan penyakit akibat kerja.

Dalam hal lamanya waktu kerja melebihi ketentuan yang telah ditetapkan (8 jam per hari atau 40 jam seminggu), maka perlu diatur waktu waktu istirahat khusus agar kemampuan kerja dan kesegaran jasmani tetap dapat dipertahankan dalam batas-batas toleransi. Pemberian waktu istirahat tersebut secara umum dimaksudkan untuk:

a. Mencegah terjadinya kelelahan yang berakibat kepada penurunan

kemampuan fisik dan mental serta kehilangan efisiensi kerja.

b. Memberi kesempatan tubuh untuk melakukan pemulihan atau penyegaran.

c. Memberikan kesempatan waktu untuk melakukan kontak sosial.

\section{Penentuan Waktu Istirahat}

Dalam penentuan konsumsi energi biasanya digunakan suatu bentuk hubungan energi dengan kecepatan denyut jantung yaitu sebuah persamaan regresi kuadratis sebagai berikut :

$\mathrm{E}=1,80411-0,0229038 \mathrm{X}+4,71733 \times 10-4 \mathrm{X} 2$

Dimana:

$\mathrm{E}=$ Energi (Kkal/menit)

$\mathrm{X}=$ Kecepatan denyut jantung/nadi (denyut/menit)

Setelah melakukan penghitungan diatas, kita dapat menghitung konsumsi energi dengan 
menggunakan persamaan :

$\mathrm{K}=\mathrm{Et}-\mathrm{Ei}$

Dimana:

$\mathrm{K}=$ Konsumsi energi (kilokalori/menit)

Et $=$ Pengeluaran energi pada waktu kerja tertentu (kilokalori/menit)

$\mathrm{Ei}=$ Pengeluaran energi pada waktu sebelum bekerja.

\section{METODE PENELITIAN}

\section{Variabel dan Definisi Operasional}

Variabel keputusan dapat dinotasikan dengan lambang X. Yang termasuk dalam indikator variabel keputusan dalam penilitian adalah sebagai berikut :
a. Kebutuhan Waktu $\left(\mathrm{X}_{1}\right)$
b. Kebutuhan Fisik $\left(\mathrm{X}_{2}\right)$
c. Kebutuhan Mental $\left(\mathrm{X}_{3}\right)$
d. Denyut Nadi $\left(\mathrm{X}_{4}\right)$

Variabel keputusan merupakan suatu indikator untuk mencapai variabel tujuan. Beban kerja meliputi beban kerja fisik dan mental. Akibat beban kerja yang terlalu berat atau kemampuan fisik yang terlalu lemah dapat mengakibatkan seorang pekerja menderita gangguan atau penyakit akibat kerja.

\section{Metode Analisa Data}

Melakukan analisis data terhadap hasil dari metode 10 denyut atau pengukuran denyut nadi, dan mengetahui seberapa besar tingkat beban kerja fisik yang di rasakan karyawan yang bekerja di lantai produksi, kemudian hasil kuesioner beban kerja mental menjadi tahapan metode Nasa-TLX.

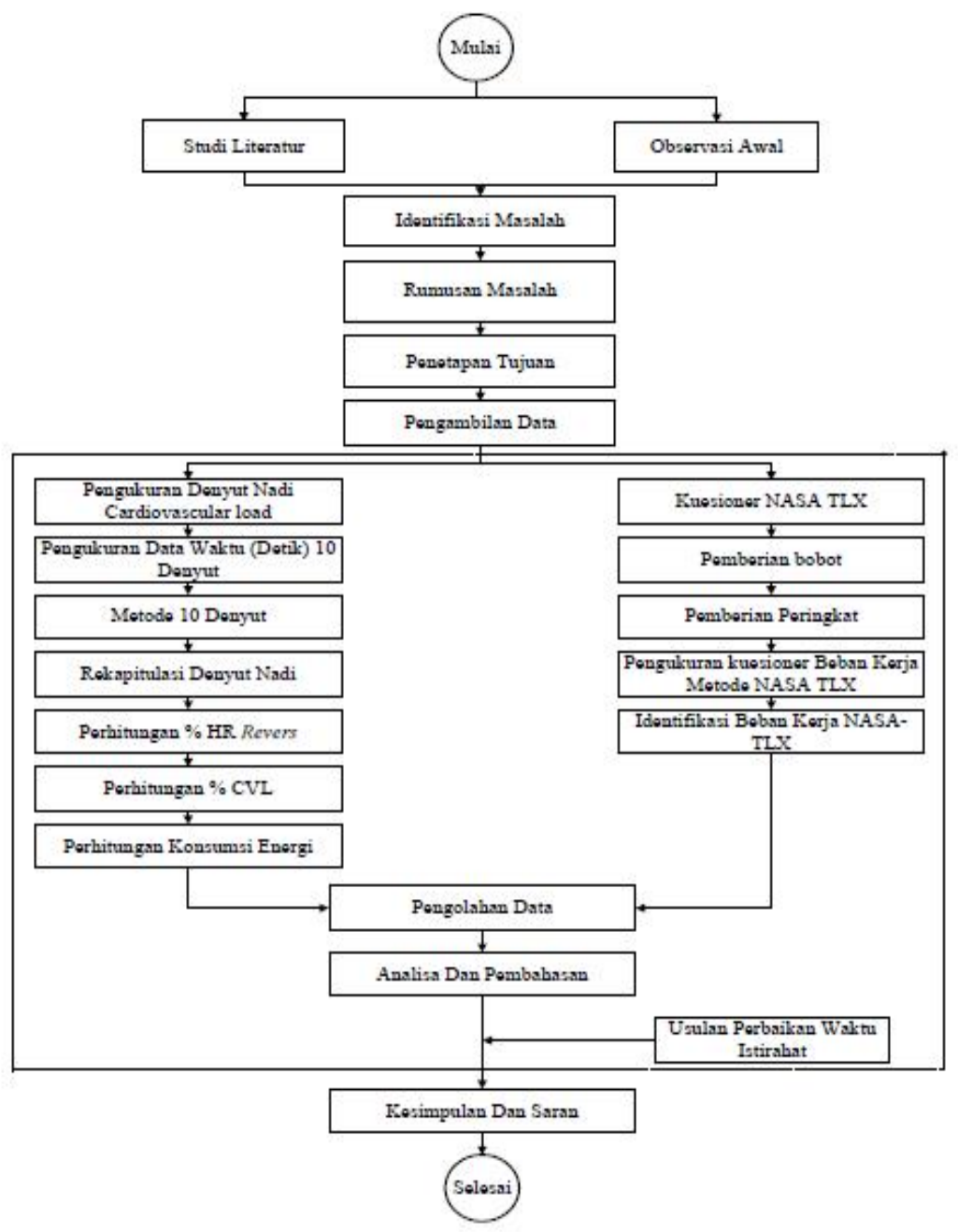

Flowchart Penelitian 
HASIL DAN PEMBAHASAN

\section{Sistem Waktu Kerja dan Proses Produksi}

Percetakan berproduksi hampir setiap hari di malam hari, kecuali hari minggu dan hari besar. beroperasi pada pukul 01:00-04:00 WIT. Bagian proses produksi PT.Fajar Utama Intermedia Cabang Ambon dibagi kedalam dua proses utama, yaitu proses pracetak dan proses cetak, yang dapat dilihat dalam bagan berikut:

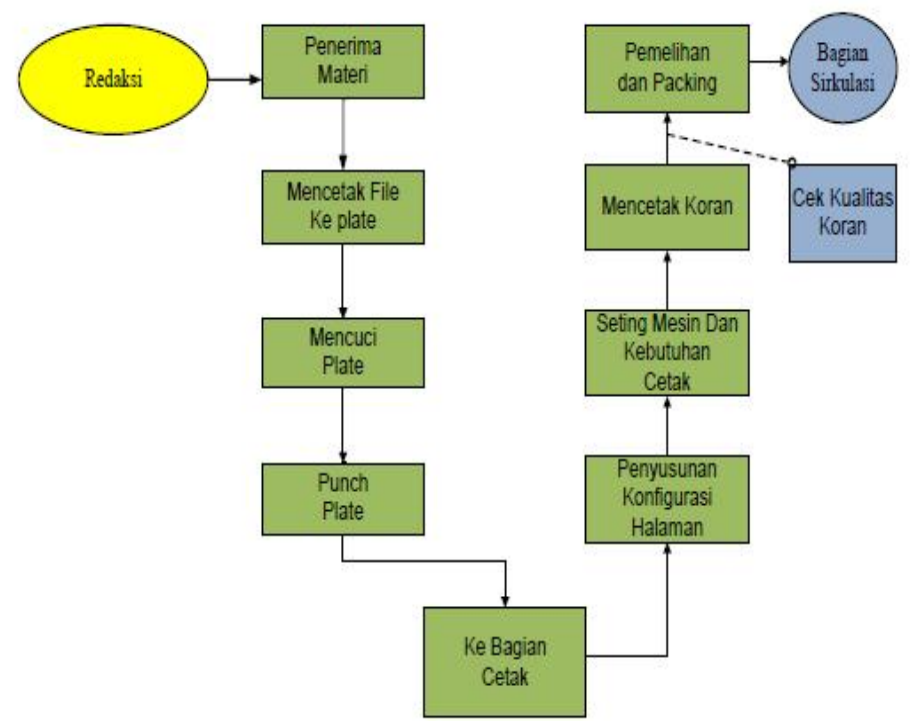

\section{Data Responden}

Gambar Proses Produksi Koran

Dari Penelitian ini data yang didapat melalui kuesioner terbuka adalah data diri dari pekerja yang berada di lantai produksi dan keluhan yang mereka rasakan selama bekerja. Data responden dapat dilihat pada Tabel dibawah ini.

Data Responden

\begin{tabular}{|l|c|l|l|l|}
\hline \multicolumn{1}{|c|}{ Nama } & Umur (Tahun) & Jenis kelamin & Status & Pendidikan \\
\hline Muhamadin & 47 & Pria & Menikah & SMA \\
\hline M waliulu & 42 & Pria & Menikah & SMA \\
\hline Trisno Silehu & 56 & Pria & Menikah & SMA \\
\hline Ismet Burhan & 50 & Pria & Menikah & Sarjana \\
\hline Ahmad Rifai & 40 & Pria & Menikah & Diploma (D3) \\
\hline
\end{tabular}

\section{Pengukuran Denyut Nadi dan Beban Kerja Mental}

Pengukuran denyut nadi dan beban kerja mental dilakukan dengan menggunakan pulse meter stopwatch dan kuesioner NASA-TLX, sampel yang diambil dari penelitian ini adalah 5 orang karyawan, penelitian dilakukan pada lantai produksi yang memproduksi Koran.

Data pengukuran denyut nadi diukur selama pekerjaan dimulai sampai dengan pekerjaan selesai dilakukan sebanyak 4 kali, dalam selang waktu masing-masing 1 jam, data denyut nadi dengan metode 10 denyut di ukur dari berapa lama waktu denyut nadi 10 denyut itu berlangsung, data denyut nadi dapat di lihat pada tabel dibawah ini.

Data Waktu Denyut Nadi

\begin{tabular}{|l|c|c|c|c|c|}
\hline \multirow{2}{*}{\multicolumn{1}{|c|}{ Nama }} & \multirow{2}{*}{ DNI (detik) } & \multicolumn{4}{|c|}{ DNK (detik) } \\
\cline { 3 - 6 } & & 1 & 2 & 3 & 4 \\
\hline Muhamadin & 8,58 & 7,3 & 6,12 & 5,3 & 5,6 \\
\hline M waliulu & 8,64 & 7,55 & 6,64 & 5,12 & 5,29 \\
\hline Trisno Silehu & 8,72 & 7,42 & 6,82 & 5,05 & 5,22 \\
\hline Ismet Burhan & 9,06 & 7,5 & 6,8 & 5,11 & 5,21 \\
\hline Ahmad Rifai & 8,6 & 7,64 & 6,87 & 5,16 & 5,02
\end{tabular}

Data pengukuran beban kerja menggunakan metode NASA-TLX menggunakan kuesioner beban kerja, didalamnya tersedia pembobotan, dan pemberian peringkat. Hasil pengukuran dapat dilihat pada tabel dibawah ini. 
pengukuran beban kerja menggunakan metode NASA-TL

\begin{tabular}{|c|c|c|c|c|c|c|c|c|c|c|c|c|}
\hline \multirow{2}{*}{ Nana } & \multicolumn{6}{|c|}{ Bobot } & \multicolumn{6}{|c|}{ Peringkat } \\
\hline & $\mathrm{MD}$ & PD & ID & $O P$ & EF & $\mathbb{F R}$ & WMD & WPD & WID & WPF & WOP & WFR \\
\hline Minhamadin & 4 & 0 & 2 & 1 & 5 & 3 & 95 & 90 & 95 & 95 & 95 & 95 \\
\hline M walinu & 3 & 1 & 2 & 3 & 1 & 5 & 95 & 90 & 95 & 95 & 90 & 95 \\
\hline Trisno Stetm & 4 & 2 & 0 & 1 & 5 & 3 & 95 & 85 & 75 & 80 & 95 & 90 \\
\hline Ismet Burhan & 3 & 0 & 1 & 4 & 2 & 5 & 85 & 55 & 75 & 95 & 85 & 95 \\
\hline Almad Rifai & 3 & 2 & 0 & 4 & 1 & 5 & 90 & 90 & 80 & 90 & 80 & 90 \\
\hline
\end{tabular}

Keterangan : (MD)Mental Demand, (PD) Phisycal Demand, (TD) Temporal Demand, (PF) Performance, (EF) Effort, (FR) Frustation. Tambahan (W) merupakan Workload / beban kerja.

\section{Penilaian Beban Kerja Dengan Metode 10 Denyut}

Metode penilaian ini adalah dengan menghitung denyut nadi selama bekerja. Pengukuran denyut jantung salama bekerja merupakan suatu metode untuk menilai cardiovasculair strain dengan metode 10 denyut (Kilbon, 1992) dimana dengan metode ini dapat dihitung denyut nadi kerja sebagai berikut :

$$
\text { Denyut Nadi (Denyut/Menit) }=\frac{10 \text { Denyut }}{\text { Waktu Per [itungan }} \times 60
$$

1.) Penilaiaan Denyut Nadi Kerja

\begin{tabular}{|c|c|c|c|c|c|c|c|}
\hline \multicolumn{8}{|c|}{ Hasil Data 10 Denyut Nadi } \\
\hline \multirow{2}{*}{ Nama } & \multirow{2}{*}{ L'mur (tahun) } & \multirow{2}{*}{ DNI (detik) } & \multicolumn{4}{|c|}{ DNK (detik) } & \multirow{2}{*}{ Rerata(detik) } \\
\hline & & & 1 & 2 & 3 & 4 & \\
\hline Muhanadin & 47 & 8,58 & 7,3 & 6,12 & 5,3 & 5,6 & 6,08 \\
\hline M walivelv & 42 & 8,64 & 7,55 & 6,64 & 5,12 & 5,29 & 6,15 \\
\hline Trisno Silehu & 56 & 8,72 & 7,42 & 6,82 & 5,05 & 5,22 & 6,13 \\
\hline Ismet Buthan & 50 & 9,06 & 7,5 & 6,8 & 5,11 & 5,21 & 6,16 \\
\hline Ahmad Rifai & 40 & 8,6 & 7,64 & 6,87 & 5,16 & 5,02 & 6,17 \\
\hline
\end{tabular}

Keterangan :

DNI : Denyut Nadi Istirahat

DNK : Denyut Nadi Kerja

Pengukuran denyut nadi istirahat dilakukan pada saat responden belum melakukan pekerjaannya.

Pengukuran denyut nadi kerja dilakukan pada saat responden telah melakukan pekerjaannya, dari saat mulai sampai dengan selesai, proses pengukuran dilakukan 4 kali yaitu pada pukul 01:00-04:00 WIT.

Hasil data waktu 10 denyut yang telah didapat pada tabel 4.4. kemudian dimasukkan dalam persamaan metode 10 denyut sehingga diperoleh denyut nadi per menit dari setiap pekerja. Hasil perhitungan dapat di lihat pada tabel dibawah ini.

2.) Perhitungan Denyut Nadi Metode 10 Denyut.

Perhitungan Denyut Nadi Metode 10 Denyut.

\begin{tabular}{|l|c|c|c|r|r|r|c|}
\hline \multirow{2}{*}{ Nama } & \multirow{2}{*}{ Umur (tahun) } & \multirow{2}{*}{ DN (denyutmenit) } & \multicolumn{4}{|c|}{ DNK (denyut menit) } & \multirow{2}{*}{ Rerata(denyut menit) } \\
\cline { 4 - 8 } & & 1 & 2 & 3 & 4 & 100,14 \\
\hline Muhamadin & 47 & 69,93 & 82,19 & 98,03 & 113,2 & 107,14 & 100 \\
\hline M waliulu & 42 & 69,44 & 79,47 & 90,36 & 117,18 & 113,42 & 100,11 \\
\hline Trisno Silehu & 56 & 68,8 & 80,86 & 87,97 & 118,81 & 114,94 & 100,65 \\
\hline Ismet Burhan & 50 & 66,22 & 80 & 88,23 & 117,41 & 115,16 & 100,20 \\
\hline Ahmad Rifai & 40 & 69,76 & 78,53 & 87,33 & 116,28 & 119,52 & 100,42 \\
\hline
\end{tabular}

3.) Rekaptulasi Denyut Nadi.

Rekaptulasi Denyut Nadi

\begin{tabular}{|l|c|c|c|c|c|}
\hline Nama & Umur(tahun) & DNI(denyut/menit & DNK(denyut/menit) & DN Maks & Nadi Kerja \\
\hline Muhamadin & 47 & 69,93 & 100,14 & 173 & 30,21 \\
\hline M waliulu & 42 & 69,44 & 100,11 & 178 & 30,67 \\
\hline Trisno Silehu & 56 & 68,8 & 100,65 & 164 & 31,85 \\
\hline Ismet Burhan & 50 & 66,22 & 100,20 & 170 & 33,98 \\
\hline Ahmad Rifai & 40 & 69,76 & 100,42 & 180 & 30,66 \\
\hline \multicolumn{2}{|c|}{ Rerata } & 68,83 & 100,30 & 173 & 31,474 \\
\hline
\end{tabular}


Keterangan :

DN Maks : Denyut Nadi Maksimal, 220 - umur untuk pria dan 200 - umur untuk wanita

Nadi Kerja : didapat dari (DNK - DNI)

Maka dari tabel 4.3. dapat dilakukan perhitungan seperti berikut :

(1) Perhitungan \% HR Revers

$$
\begin{aligned}
\% \text { HR Revers } & =\frac{D N K-D N I}{D N \text { Naks }-D N I} \times 100 \\
& =\frac{100,30-68,38}{173-68,38} \times 100 \\
& =30,51
\end{aligned}
$$

(2) Perhitungan cardiovascular strain (\%CVL)

$$
\begin{aligned}
\% \text { CVL } & =\frac{100 \times(\text { DNK }-D N I)}{\text { DN Maks }-D N I} \\
& =\frac{100 \times(100,30-68,38}{173-68,38} \\
& =30,51
\end{aligned}
$$

(3) Perhitungan Konsumsi energi (Energy Expenditure)

$$
\begin{aligned}
\mathrm{E} & =1,80411-0,0229038 \mathrm{X}+4,71733 \times 10^{-4} \mathrm{X} 2 \\
& =1,80411-0,0229038(100,30)+4,71733 \times 10^{-4}(100,30)^{2} \\
& =4,252535296
\end{aligned}
$$

\section{Penilaian Beban Kerja Menggunakan Metode NASA-TLX}

NASA-TLX merupakan salah satu metode subjektif yang digunakan untuk dalam pengukuran beban kerja mental yang diterima oleh individu. Metode NASA-TLX merupakan salah satu metode yang paling banyak digunakan dan terbukti memberikan hasil yang cukup baik menurut Hancock dan Meshkati (1988). Beban Kerja NASA-TLX dapat di hitung dengan rumus sebagai berikut :

$(\underline{\mathrm{WMD} R M D+\mathrm{WPD} \times \mathrm{RPD}+\mathrm{WTD} \times \mathrm{RTD}+\mathrm{WOP} \times \mathrm{ROP}+\mathrm{WEF} \times \mathrm{REF}+\mathrm{WFR} \times \mathrm{RFR})}$

1.) Perhitungan Beban Kerja Metode NASA-TLX

Muhammadin.

$$
\begin{aligned}
\text { Workload NASA-TLX } & =\frac{(95 \times 4+90 \times 0+95 \times 2+95 \times 1+95 \times 5+95 \times 3)}{15} \\
& =\frac{1425}{15} \\
& =95
\end{aligned}
$$

M Waiulu.

$$
\begin{aligned}
\text { Workload NASA-TLX } & =\frac{(95 \times 3+90 \times 1+95 \times 2+95 \times 3+90 \times 1+95 \times 5)}{15} \\
& =\frac{1415}{15} \\
& =94,3
\end{aligned}
$$

Trisno Silehu.

$$
\begin{aligned}
\text { Workload NASA-TLX } & =\frac{(95 \times 4+85 \times 2+75 \times 0+80 \times 1+95 \times 5+90 \times 3)}{15} \\
& =\frac{1375}{15} \\
& =92
\end{aligned}
$$

\section{Pengukuran Waktu Istirahat.}

Dari penelitian yang dilakukan nilai konsumsi energi yang dihasilkan adalah 4,252535296 Kkal/min, hasil ini kemudian dapat di hitung atau dikonversikan kedalam kebutuhan waktu istirahat dengan menggunakan persamaan Murrel (Pullat, 1992) sebagai berikut :

$$
\mathrm{Rt}=\frac{K / S 1 x T(K \cdot S) / . B M}{2} \quad \text { untukS }<\mathrm{K}<2 \mathrm{~S}
$$

Alasan mengapa memakai persamaan ini dikarenakan nilai data hasil penelitian ini atau konsumsi energi lebih kecil dari standar energi yang dikeluarkan yaitu $K=4,252535296$ dan $S=5$ (standar energi yang dikeluarkan pria). Perhitungan waktu istirahat yaitu : 


$$
\begin{aligned}
\text { Rt } & =\frac{K / S 1 \times T(K . S) / . B M}{2} \\
\text { Rt } & =\frac{4,252535296 / 5 \times 240(4,252535296 \times 5) / 1,7}{2} \\
& =\frac{2553.043263}{2} \\
& =1276,521631 \text { menit. }
\end{aligned}
$$

Jadi hasil dari perhitungan waktu istirahat adalah 1276,521631 menit dan di konversikan ke dalam jam adalah 21,27536052, atau 21 jam istirahat untuk pekerja yang bekerja di lantai produksi.

\section{Analisa Data}

Penilaian Beban Kerja Fisik

Kategori beban kerja pada metode ini ditentukan melalui variabel yaitu: beban cardiovaskuler (\% CVL), bisa juga dengan menghitung konsumsi energi. Dari hasil pengolahan dengan metode ini dapat dilihat pada tabel dibawah ini.

Hasil Penilaian Beban Kerja 10 denyut

\begin{tabular}{|c|l|c|}
\hline NO & \multicolumn{1}{|c|}{ Keterangan } & Hasil \\
\hline 1 & Rerata DNI (Denyut Nadi Istirahat) & 68,83 \\
\hline 2 & $\begin{array}{l}\text { Rerata DN Maks (Denyut Nadi } \\
\text { Maksimal) }\end{array}$ & 173 \\
\hline 3 & Rerata NK (Nadi Kerja) & 31,47 \\
\hline 4 & Rerata DNK (Denyut Nadi Kerja) & 100,30 \\
\hline 5 & HR Revers (\%) & 30,51 \\
\hline 6 & CVL $(\%)$ & 30,51 \\
\hline 7 & Energy Expenditure $(\mathrm{Kkal} / \mathrm{min})$ & 4,252535296 \\
\hline
\end{tabular}

Dari tabel diatas dapat dilihat bahwa rerata denyut nadi istirahat karyawan pada lantai produksi adalah 68,83 denyut/menit, hal ini sesuai dengan daftar frekuensi denyut nadi menurut umur yaitu pada umur $>14$ dengan fekuensi nadi sebesar 60-100 denyut/menit, untuk frekuensi umur >14 adalah termasuk umur dewasa. Daftar tabel frekuensi denyut nadi menurut umur dapat di lihat pada tabel 2.2. Rerata denyut nadi maksimal adalah 173 denyut/menit, rerata nadi kerja 31,47\%. \% CVL diklasifikasikan pada beban kerja sedang karena berkisar 100- 125 denyut, hasil dari nilai denyut nadi kerja bernilai 100,30 denyut/menit dan \%CVL 30,51\%, jika dilihat dari tabel klasifikasi berat atau ringannya beban kerja

\%CVL 30,51\% adalah termasuk beban kerja yang harus memerlukan perbaikan agar meminimasi kelelahan kerja. Kemudian untuk konsumsi energi (Energy Expenditure) tergolong dalam beban kerja ringan dengan hasil nilai yaitu 4,252535296.

\section{Penilaian Beban Kerja Mental}

Berdasarkan hasil perhitungan beban kerja mental menggunakan metode NASA TLX, Faktor yang paling dominan mempengaruhi beban kerja mental dapat diketahui dengan cara melihat hasil dari seberapa sering indikator dipilih oleh responden. Faktor dominan dapat dilihat pada gambar dibawah ini.

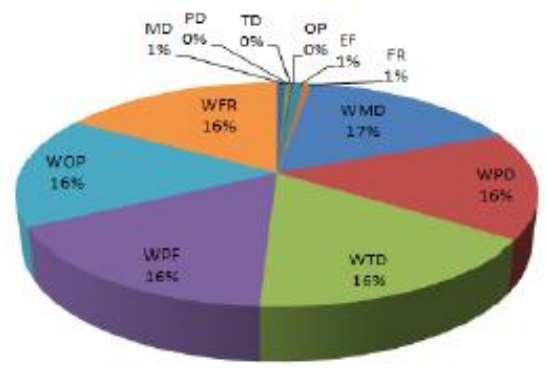

Chart Beban Kerja Dominan

Keterangan : (MD)Mental Demand, (PD) Phisycal Demand, (TD) Temporal Demand, (PF) Performance, (EF) Effort, (FR) Frustation. Tambahan (W) merupakan Workload / beban kerja.

Berdasarkan gambar diatas indikator bobot yang memiliki nilai skor yang dominan dipilih masingmasing dengan nilai $1 \%$ adalah bobot MD (Mental Demand) atau kebutuhan mental, bobot EF (Effort) atau 
tingkat usaha, dan bobot FR (frustation) atau tingkat frustasi, sedangkan 3 indikator lain adalah indicator yang paling jarang dipilih yaitu PD (Physical Demand) atau kebutuhan fisik, TD (Temporal Demand) atau kebutuhan waktu, dan OP (Own Performance) atau perfomansi. Kemudian untuk beban kerja (Workload) indikator yang paling dominan dipilih adalah WMD (Workload Mental Demand) dengan nilai 17\% dan 5 indikator lain masing-masing setara yaitu dengan nilai $16 \%$.

Berdasarkan hasil perhitungan beban kerja mental menggunakan metode NASA TLX, didapatkan hasil skor NASA TLX seperti pada tabel 4.9. dibawah ini.

Hasil Skor NASA-TLX.

\begin{tabular}{|l|c|}
\multicolumn{1}{|c|}{ Nama } & Workload \\
\hline Muhamadin & 95 \\
\hline M waliulu & 94,3 \\
\hline $\begin{array}{l}\text { Trisno } \\
\text { Silehu }\end{array}$ & 92 \\
\hline $\begin{array}{l}\text { Ismet } \\
\text { Burhan }\end{array}$ & 90,3 \\
\hline $\begin{array}{l}\text { Ahmad } \\
\text { Rifai }\end{array}$ & 91 \\
$\begin{array}{l}\text { Jumlah } \\
\text { Rerata }\end{array}$ & 462,6 \\
\hline
\end{tabular}

Tabel diatas menunjukan bahwa masing-masing pekerja memiliki beban kerja yang tinggi yaitu dengan nilai rerata beban kerja yang dimiliki yaitu 92,52, berdasarkan klasifikasi beban kerja NASA-TLX, nilai 80-100 adalah beban kerja yang sangat berat, jadi rerata yang didapat dari perhitungan NASA-TLX dengan nilai 92,52 adalah beban kerja mental yang sangat berat di lakukan oleh pekerja dilantai produksi.

\section{Hasil Penentuan Waktu Istirahat}

Dari hasil penelitian yang dilakukan nilai penentuan waktu istirahat adalah 1276 menit dan dikonversikan ke dalam satuan jam yaitu 21 jam, waktu kerja yang ditentukan oleh perusahaan untuk pekerja dilantai produksi adalah 4 jam, dalam hal ini dapat dikatakan bahwa pekerja harus istirahat dalam waktu 21 jam sebelum bekerja dan sisa waktu dipakai untuk bekerja pada malam hari yaitu 3 jam. Hasil perhitungan penentuan waktu istirahat dapat dilihat pada tabel dibawah.

Hasil Penentuan Waktu Istirahat

\begin{tabular}{|l|c|}
\hline \multicolumn{1}{|c|}{ Keterangan } & Hasil \\
\hline Rt (Waktu istirahat) & 1276,521631 menit \\
\hline $\begin{array}{l}\text { Konversi ke Jam }=1276 \$ 521631 \\
\text { menit/60 menit }\end{array}$ & $21,27536052 \mathrm{Jam}$ \\
\hline
\end{tabular}

\section{Usulan Waktu Istirahat}

Data yang didapat dari penelitian yang dilakukan, adalah beberapa pekerja memiliki waktu kerja malam di lantai produksi dan diwaktu siang adalah pekerjaan tambahan, hal ini dapat menyebabkan gangguan mental maupun fisik, karena dari pekerjaan malam yang mereka lakukan, fungsi fisiologi benilai rendah, sebagai contoh suhu inti dan detak jantung mengawali irama diurnal tubuh. Yang didukung oleh ketidak aktifan pada malam hari. Selama siang aktivitas puncak biasanya bertepatan dengan nilai tinggi dari fungsi internal. Biasanya pengamatan irama diurnal diperoleh berdasarkan hasil internal (endogenous) dan eksternal (exogenous) yang terjadi. Jika terjadi ketidak seimbangan antara keduanya tersebut dapat muncul permasalahan kesehatan. Jadi dari hasil perhitungan waktu istirahat yaitu dengan nilai 1276 menit atau 21 jam dapat diusulkan kepada para pekerja sebagai waktu istirahat yang efektif sebelum memulai pekerjaan saat malam hari, agar kemampuan kerja dan kesegaran jasmani tetap dapat dipertahankan dalam batas-batas toleransi. Pemberian waktu istirahat tersebut secara umum dimaksudkan untuk:

a. Mencegah terjadinya kelelahan yang berakibat kepada penurunan kemampuan

fisik dan mental serta kehilangan efisiensi kerja.

b. Memberi kesempatan tubuh untuk melakukan pemulihan atau penyegaran.

c. Memberikan kesempatan waktu untuk melakukan kontak sosial.

\section{KESIMPULAN}

Berdasarkan hasil penelitian dapat diambil kesimpulan sebagai berikut:

1. Hasil Beban kerja fisik dengan metode cardiovascularload adalah rerata DNI (denyut Nadi Istirahat) dengan nilai 68,83, rerata DNK (denyut Nadi Kerja) dengan nilai 100,3, rerata Denyut Nadi maksimal dengan nilai 173, rerata Nadi Kerja dengan nilai 31,47, persentase Heart Revers dan persentase 
cardiovascular dengan nilai 30,51\%, dan Energy Expenditure dengan nilai 4,252535296 Kkal/menit. Dari hasil \%CVL menunjukkan bahwa nilai 30,51\% adalah beban kerja sedang bagi para pekerja, jika dilihat dari klasifikasi \%CVL maka harus dilakukan perbaikan. Kemudian dari hasil penelitian untuk beban kerja mental, masing-masing pekerja adalah muhamadin dengan nilai beban kerja 95, M waiulu dengan nilai beban kerja 94,3, Trisno Silehu dengan nilai beban kerja 92, Ismet Burhan dengan nilai beban kerja 90,3, dan Ahmad rifai dengan nilai beban kerja 91. Dari semua nilai beban kerja masingmasing pekerja dapat dilihat bahwa beban kerja memiliki rerata yaitu 95,52\%, jika dilihat dari klasifikasi beban kerja NASA-TLX nilai tersebut menandakan bahwa pekerja memiliki beban kerja yang sangat tinggi.

2. Berdasar hasil perhitungan untuk penentuan waktu istirahat melalui perhitungan konsumsi energi yang dibutuhkan selama bekerja yang dikonversikan kedalam kebutuhan waktu istirahat menyatakan bahwa hasil perhitungan waktu istirahat yaitu dengan nilai 1276 menit atau 21 jam dapat diusulkan kepada para pekerja sebagai waktu istirahat yang efektif sebelum memulai pekerjaan saat malam hari, agar kemampuan kerja dan kesegaran jasmani tetap dapat dipertahankan dalam batas-batas toleransi. Pemberian waktu istirahat tersebut secara umum dimaksudkan untuk:

a) Mencegah terjadinya kelelahan yang berakibat kepada penurunan kemampuan fisik dan mental serta kehilangan efisiensi kerja. perhitungan waktu istirahat yaitu dengan nilai 1276 menit atau 21 jam dapat diusulkan kepada para pekerja sebagai waktu istirahat yang efektif sebelum memulai pekerjaan saat malam hari, agar kemampuan kerja dan kesegaran jasmani tetap dapat dipertahankan dalam batas-batas toleransi.

b) Memberi kesempatan tubuh untuk melakukan pemulihan atau penyegaran.

c) Memberikan kesempatan waktu untuk melakukan kontak sosial.

\section{DAFTAR PUSTAKA}

Atik Muftia, (2005)., Hubungan antara Faktor Fisik dengan Kelelahan Kerja di PT. Sinar Sastro Ungarang Semarang, Skripsi. Semarang: UNDIP.

As'ad, M. (1987)., Hubungan Faktor Umur, Pendidikan, Masa Kerja dan Kepuasan Kerja terhadap Produktifitas Kerja pada Petugas Dinas Luar Asuransi. Penelitian Fakultas Psikologi UGM, Yogyakarta.

Antara, News (2010)., Angka Kecelakaan Kerja Tahun Turun. http://apindo.or.id/index.php/berita-aartikel/kliping/371-angkakecelakaan- kerja-\%20ahun-2010-turun (diakses tanggal 24 juli 2018)

Attwood Dennis A, Joseph M, Danz-Reece Mary E. (2004)., Ergonomic Solution For The Process Industries. Elsevier Inc. Barlington USA.

Depdikbud. (1996)., Ketahuilah Tingkat Kesegaran Jasmani Anda. Pusat Kesegaran Jasmani dan Rekreasi Departemen Pendidikan dan Kebudayaan. Jakarta.

Guyton (1990), Fisiologi Manusia dan Mekanisme Penyakit Edisi III. EGC. Jakarta.

Grandjean, E. (1993)., Fitting the task to the man, $4^{\text {th }}$ ad. Taylor \& Francis Inc". London.

Henni, Nurina, Syifa Fauziah Abbas. (2011), Analisis Pengaruh Shift Kerja Terhadap Beban Kerja Dengan Menggunakan Metode SWAT. Universitas Persada Indonesia, Teknik Industri.

Hatapayo M Zulfikar (2017)., Analisis Beban Kerja shift pada Perawat Ruang Unit Gawat Darurat (UGD) dengan metode 10 denyut (studi kasus : rumah sakit umur daerah masohi) Skripsi Universitas Pattimura Ambon."

Kuswadji, S. (1997)., Pengaturan Tidur Pekerja Shif., Cermin Dunia Kedokteran No. 116/1997, 48 - 52. Jakarta.

Manuaba, A.(2000)., Ergonomi, Kesehatan dan Keselamatan kerja, Proceeding Seminar Nasional Ergonomi. Editor : Wignyosoebroto,S \& Wiranto, S.E Guna Widya, Surabaya.

Marras, W. dan Karwowski, W. (2006)., Fundamentals and Assesment Tools For Occupational Ergonomicsm. Third Edition, Taylor and Francis. Boca Raton.

Pamungkas Sekar Rachma.(2017)., Analisis Beban Kerja di Bagian Pengepakan. (Studi Kasus : PT Perkebunan Nusantara IX Kebun Batujamus Pabrik RSS Kerjoarum Karanganyar). Skripsi, Universitas Muhammadiyah Surakarta.

Widodo, S. (2008). Penentuan Lama Waktu Istirahat Berdasarkan Beban Kerja dengan Menggunakan Pendekatan Fisiologis (Studi Kasus pada Pabrik Minyak Kayu Putih Krai, Jawa Tengah). Skripsi, Universitas Muhammadiyah Surakarta. 